\title{
Diagnosis of primary site of tumour origin using immunohistochemistry on cell block in cases of malignant ascitic fluid
}

\author{
Patel TS. ${ }^{1}$, Goel DK. ${ }^{2 *}$, Trivedi PP. ${ }^{3}$, Patel SP. ${ }^{4}$, Mehta SP. ${ }^{5}$ \\ DOI: https://doi.org/10.17511/jopm.2020.i01.07
}

\footnotetext{
1 Trupti S. Patel, Associate Professor, Department of Pathology, Gujarat Cancer Research Institute, Ahmedabad, Gujarat, India.

2* Deepak K. Goel, Resident Doctor, Department of Pathology, Gujarat Cancer Research Institute, Ahmedabad, Gujarat, India.

3 Priti P. Trivedi, Professor and Head of Department, Department of Pathology, Gujarat Cancer Research Institute, Ahmedabad, Gujarat, India.

4 Suchita P. Patel, Senior Resident, Department of Pathology, Gujarat Cancer Research Institute, Ahmedabad, Gujarat, India.

5 Shailee P Mehta, Assistant Professor, Department of Pathology, Gujarat Cancer Research Institute, Ahmedabad, Gujarat, India.
}

Introduction: Presence of malignant cells in peritoneal fluid has serious implications as most of the times, it represents a metastasis from a distant organ, along with poor prognosis. Aim: 1) To ascertain primary site of origin from malignant ascitic fluid cases using cytoblock preparation and immunohistochemistry. 2) To find out frequency of various cancers from different parts of the body in malignant peritoneal fluid. Materials and methods: This is retrospective cross-sectional observation-based study in which 200 cases of malignant peritoneal fluid were studied and analysed. Routine clinical data, radiological investigations, histopathological diagnosis, cytomorphological features and immunohistochemistry were considered and statistically analysed. Results: 1) Malignant ascitic fluid cases are more common in older age group of patients and females outnumber the male patients substantially. 2) Adenocarcinoma is the most common histological type. 3) Ovary is the most common primary site of malignant peritoneal effusion. 4) Cytoblock preparation and immunohistochemistry on cytoblock can be very helpful in finding the primary site of origin in those cases where patients first presented to the hospital with signs of malignant ascites and no symptomatology related to primary site. Conclusion: Cytological examination of serous effusions is an accurate, prompt, affordable technique having diagnostic and therapeutic implications. With the help of ancillary methods, the phenotype of cells can be identified, classify as well as confirm our diagnosis.

Keywords: Malignant ascites, Cell block, Immunohistochemistry, Primary site of origin

Corresponding Author

Deepak K. Goel, Resident Doctor, Department of Pathology, Gujarat Cancer Research Institute, Ahmedabad, Gujarat, India. Email: drdpkgoel@gmail.com

\section{How to Cite this Article}

Patel TS, Goel DS, Trivedi PP, Patel SP, Mehta SP. Diagnosis of primary site of tumour origin using immunohistochemistry on cell block in cases of malignant ascitic fluid. Trop J Pathol Microbiol. $2020 ; 6(1): 43-49$.

Available From

https://pathology.medresearch.in/index.php/jopm/ar ticle/view/411

\section{To Browse}

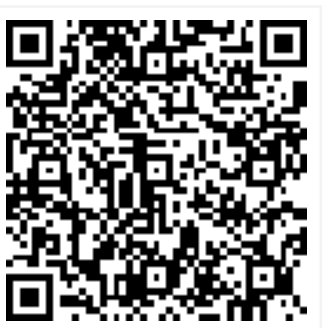

Manuscript Received 26-12-2019

Conflict of Interest No

Review Round 1
04-01-2020
Funding
Nil

Review Round 1

$\mathrm{Nil}$

Review Round 2
10-01-2020
Ethical Approval
Yes

Yes
Review Round 3

Plagiarism X-checker $11 \%$
Accepted 14-01-2020

(c) 2020 by Trupti S. Patel, Deepak K. Goel, Priti P. Trivedi, Suchita P. Patel, Shailee P Mehta and Published by Siddharth Health Research and Social Welfare Society. This is an Open Access article licensed under a Creative Commons Attribution 4.0 International License https://creativecommons.org/licenses/by/4.0/ unported [CC BY 4.0]. 


\section{Introduction}

Cytological examination of peritoneal fluids is a routine diagnostic procedure in most laboratories. It is significant for its diagnostic, therapeutic and prognostic implications. Malignant peritoneal effusions are mostly manifestation of a metastatic disease and many-a-time it is the only clinical clue of an unknown primary. Cancers commonly associated with the development of ascites include female genital tract, gastrointestinal tract, pancreatobiliary tract and breast $[1,2]$.

Followed by NHL and lung, prostate or germ cell primary. Although multiple aetiologies namely cirrhosis $(81 \%)$, heart failure $(3 \%)$, tuberculosis (2\%) can lead to ascites, around $7 \%$ to $10 \%$ of cases can be attributed secondary to a malignancy [3]. The development of malignant ascites carries a poor prognosis, with the median survival reported anywhere between 1 and 4 months [4].

Hence, not only it is imperative for the treating clinician to know whether malignancy is present, but also to know which lineage these malignant cells belong to and its primary site of origin, as it is the deciding factor in planning subsequent management protocols for the patient. When it is not possible to obtain tissue biopsy from the primary site due to radiologically undetected lesions. extensive fibrosis, massive ascitis in cases of intraabdominal malignancies. In such cases, diagnosis made by fluid block preparations, can help to initiate early treatment [5].

The present study tried to assess the importance of utilization of Cytoblock (CB) coupled with immunohistochemistry (IHC) on ascitic fluid samples to arrive at a definitive diagnosis and decide its primary site of origin in cases where patient presents with malignant ascites with unknown primary. In this study, cell block preparations were used to arrive to a diagnosis in cases which either showed malignant cells and suspicious/reactive mesothelial cells in ascitic fluid. Cell blocks prepared from residual fluid provide excellent opportunity to see the tissue architecture as it relatively gets preserved which aids in diagnosis. The technique is very cost effective, reproducible and safe [6].

Availability of the serial sections made from the serous fluids for the further histological examination, special staining, immunohistochemistry is also unique feature of this
Technique. The diagnosis of malignancy could be made more reliable by examination of threedimensional cell clusters, details of morphological features in their proper perspective i.e., the presence of the nucleoli and the acinar structures, cell balls or distinct papillary architecture [7]. Cellblock technique has its own set of limitations such as more processing time compared to conventional smears and risk of loss of tissue during the processing. Centrifugation artefacts may form rosettes or pseudo acini \& may cause a misdiagnosis $[6,8]$.

The present study had analysed 200 cases of malignant ascitic fluid samples received at our centre for a period of one year to assess the utility of $C B$ in conjunction with IHC to locate the primary site of malignancy.

\section{Materials and Methods}

An observational and analytical retrospective crosssectional study of ascitic fluid samples received at the Cytology Department of a Gujarat Cancer Research Institute, Ahmedabad from January to December 2017 was carried out.

Inclusion criterion: All malignancies associated with peritoneal effusion detected in any age group was included in the present study. Both haematological and non-haematological malignancies and malignancies with known/unknown primary were considered for this study.

Exclusion criterion: All other body fluids except the peritoneal fluid was excluded from the study. Routine haematological, radiological and tumour marker study was carried out.

Two smears were immediately fixed with alcoholether solution (1:1) and stained with PAP stain and examined. Rest of the fluid was homogenised and processed for cell block (CB) preparations. The CB was subsequently processed as a routine surgical tissue. The $C B$ sections were stained with Haematoxylin and Eosin (H \& E) stain.

The slides were reported in the following format: no malignant cell seen/atypical cells present/suspicious for malignancy/positive for malignant cell. In 31 cases where primary site of origin was unknown, immunocytochemistry (ICC) was applied on the cyto block preparations to ascertain the primary site of origin. Immunocytochemistry was done by fully automated machine VENTANA BENCHMARK XT. 
Immunohistochemistry was done wherever required from the primary site to reach the conclusive diagnosis. bone marrow aspiration and biopsy were done to reach the final diagnosis. Also, flow cytometry using FACS Canto II flow cytometer (6color, 2-Laser, BD Biosciences USA) and analysed using FACS Diva software was carried out to confirm our diagnosis in haematological malignancies The relevant clinical features and cytomorphological findings of CS and CB preparation were entered as an excel data sheet. Statistical analysis was carried out.

\section{Results}

Out of the 662 ascitic fluid for cell block preparation requests were received 182 cases were positive, 18 cases were suspicious and 462 were negative on cytological examination.18 suspicious cases turned out to be positive on repeat aspiration. Hence, 200 cases were included in this study out of which primary site was known in 160 cases, in 31 cases primary site was not known and 9 cases were lost to follow up. The result of analysis of 200 malignant cases of ascitic fluid under different headings are as follows

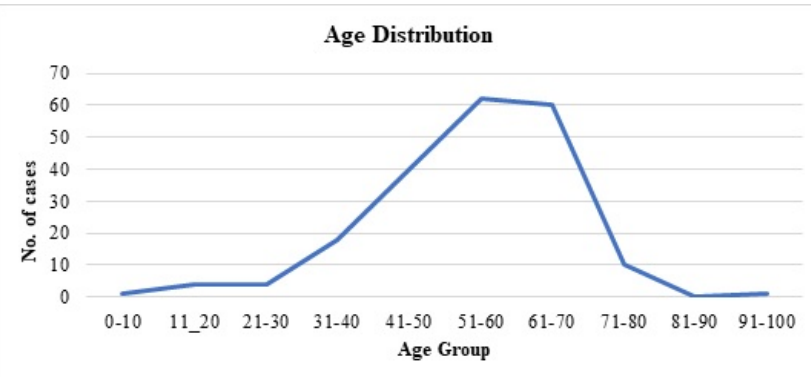

Fig-1: Age distribution.

- Malignant ascitic effusions are most common in fifth (31\%) and sixth (30\%) decade of life followed by the fourth decade (20\%).

- Mean age is 54 years (Figure 1 )

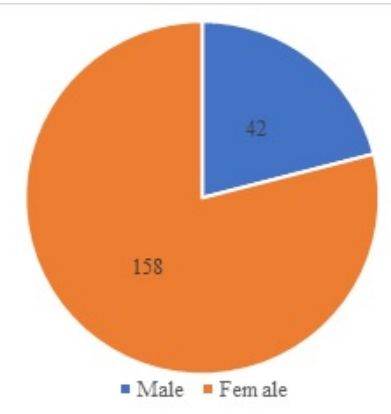

Fig- 2: Sex distribution.
- Male: female ratio $-1: 3.8$

- Malignant peritoneal effusions are far more common in females than male patients (Figure 2).

Table-1: Site of primary origin.

\begin{tabular}{|c|c|c|}
\hline Site & $\begin{array}{l}\text { No of cases } \\
(\%)\end{array}$ & Histological type \\
\hline \multirow[t]{3}{*}{ Ovary } & \multirow[t]{3}{*}{$108(54 \%)$} & $\begin{array}{l}\text { Serous papillary adenocarcinoma } \\
(105)\end{array}$ \\
\hline & & Mucinous adenocarcinoma (1) \\
\hline & & Poorly differentiated carcinoma (2) \\
\hline Stomach & $24(12 \%)$ & Adenocarcinoma (24) \\
\hline \multirow{2}{*}{$\begin{array}{l}\text { Pancreatobiliary } \\
\text { system }\end{array}$} & \multirow[t]{2}{*}{$12(6 \%)$} & Pancreatic adenocarcinoma (6) \\
\hline & & Biliary tract adenocarcinoma (6) \\
\hline Haematological & $11(5.5 \%)$ & \\
\hline Lost to follow up & $9(4.5 \%)$ & Metastatic adenocarcinoma (9) \\
\hline Colon & $7(3.5 \%)$ & Adenocarcinoma (7) \\
\hline \multirow[t]{2}{*}{ Breast } & \multirow[t]{2}{*}{$5(2.5 \%)$} & Ductal carcinoma (4) \\
\hline & & Lobular carcinoma (1) \\
\hline Rectum & $5(2.5 \%)$ & Adenocarcinoma (5) \\
\hline Lung & $5(2.5 \%)$ & Adenocarcinoma (5) \\
\hline Cervix & $4(2 \%)$ & Squamous cell carcinoma (4) \\
\hline Oesophagus & $4(2 \%)$ & Adenocarcinoma (3) \\
\hline Bladder & $3(1.5 \%)$ & Urothelial carcinoma (3) \\
\hline $\begin{array}{l}\text { Tongue + Buccal } \\
\text { Mucosa }\end{array}$ & $3(1.5 \%)$ & Squamous cell carcinoma (3) \\
\hline Total & $200(100 \%)$ & \\
\hline
\end{tabular}

It is clearly depicted that Ovary is most common primary site followed by Gastrointestinal tumours.

Table-2: Haematological malignancies
diagnosed on ascitic fluid cytology.

\begin{tabular}{|l|l|}
\hline \multicolumn{1}{|c|}{ Type } & $\begin{array}{c}\text { No of cases } \\
(\%)\end{array}$ \\
\hline $\begin{array}{l}\text { ALL/ lymphoblastic lymphoma (Including 2 cases of } \\
\text { Burkitt's leukemia) }\end{array}$ & $5(45 \%)$ \\
\hline DLBCL & $4(36 \%)$ \\
\hline CML-BC & $2(18 \%)$ \\
\hline Total & $11(100 \%)$ \\
\hline
\end{tabular}

Nine cases were lost to follow up and their primary site could not be ascertained. In 31 cases as mentioned above primary site of origin was unknown and hence a battery of immunohistochemical markers was applied to reach the final diagnosis which was confirmed on biopsy from the primary site.

\section{Discussion}

A single layer of flat mesothelial cells lines the body cavities known as serosa Ascites is the pathologic 
Accumulation of fluid more than $25 \mathrm{ml}$ within the peritoneal cavity [9]. Most common cause of abnormal accumulation of fluid in peritoneal cavity is liver cirrhosis ( $80 \%$ ) with approximately $10 \%$ of cases being caused by malignancies. Lucke and Klebs first demonstrated atypical cells in ascitic fluid in 1867 [10].

The examination of body fluids for the presence of malignant cells has been accepted as a routine laboratory procedure, not only for the detection of unsuspected cancers, but also for the detection of metastasis of an unknown primary origin. In case of malignant lesions, it also helps in the staging of these lesions.

Presence of malignant cells in serous fluids are almost always suggestive of metastatic tumours, as primary malignancies are usually rare. Ascitic fluid has a much higher rate of detecting malignant cells especially if the aspirate is bloody. It is a common complication and indication of advance stage of malignancies [11].

In the present study, $81 \%$ of the cases of malignant peritoneal effusions, fell under 40-70 years age group with a mean age of 54 years. This age group coincides with the peak age group of the patients harbouring the causative malignancies. Females have almost four times more chances to develop malignant peritoneal effusions, due to marked association of ascites with gynaecological malignancies.

In a similar study done by AA Ayutunde and parsons [2] mean age was found to be 67 years, significantly higher than the present study and female to male patients' ratio was $2: 1$. Aetiology of malignant peritoneal effusion are almost entirely because of carcinomas and extremely rarely due to sarcomas [12].

Out of 200 cases, 189 were of epithelial origin and only 11 were of haematological origin. Adenocarcinoma was the most common type of carcinoma to cause malignant peritoneal effusion $(89.5 \%)$ in the present study, followed by lymphoma $(5.5 \%)$ and squamous carcinoma $(3.5 \%)$. The present results were similar to a study done by Malik et al [13] in which most cases of malignant peritoneal effusions were due to adenocarcinomas ( $82 \%$ ) followed by non-Hodgkin's lymphomas (11\%). Ovarian malignancies were the most common cause of malignant peritoneal effusions (54\%) in the present study.
In retrospective review of 164 consecutive patients with malignant ascites done by Parsons et al [14] it has been shown that ovarian ascites accounts for $28 \%$ of the total and is associated with a significantly improved survival compared with other groups. In various other studies ovarian cancers accounted for 30-54\% cases of malignant ascites [14].

Ovarian Serous papillary adenocarcinoma was the most common histological variety with only single case of mucinous adenocarcinoma being detected in peritoneal effusion due to ovarian malignancies (Figure 3). In a study done by Elizabeth et al [15] serous adenocarcinoma accounted for 90-95\% cases of malignant ascites caused due to ovarian malignancies.

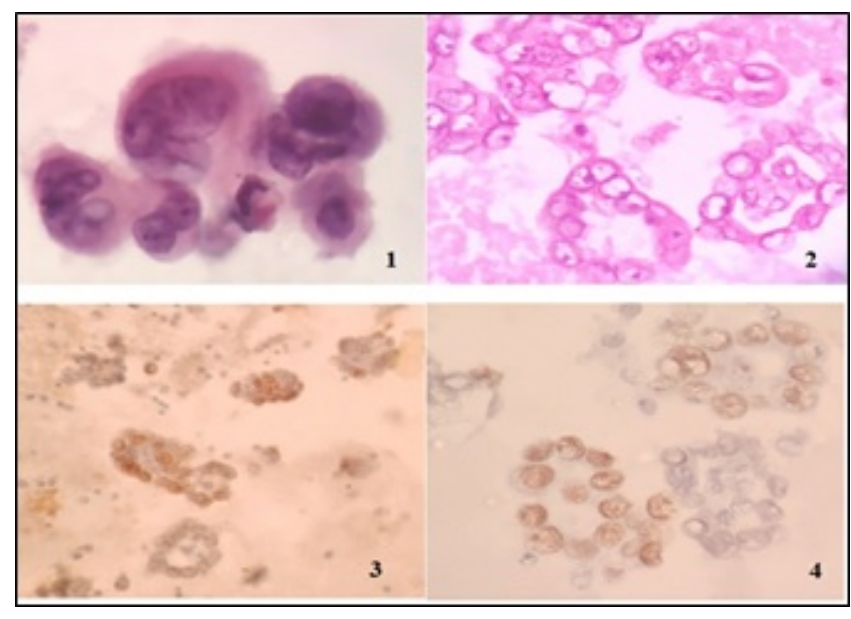

Fig-3: Metastatic serous papillary adenocarcinoma in ascitic fluid from ovarian primary (1) Cell smear 100x (2) Cell block 100X (3) PAX 8 positive (4) WT1 positive.

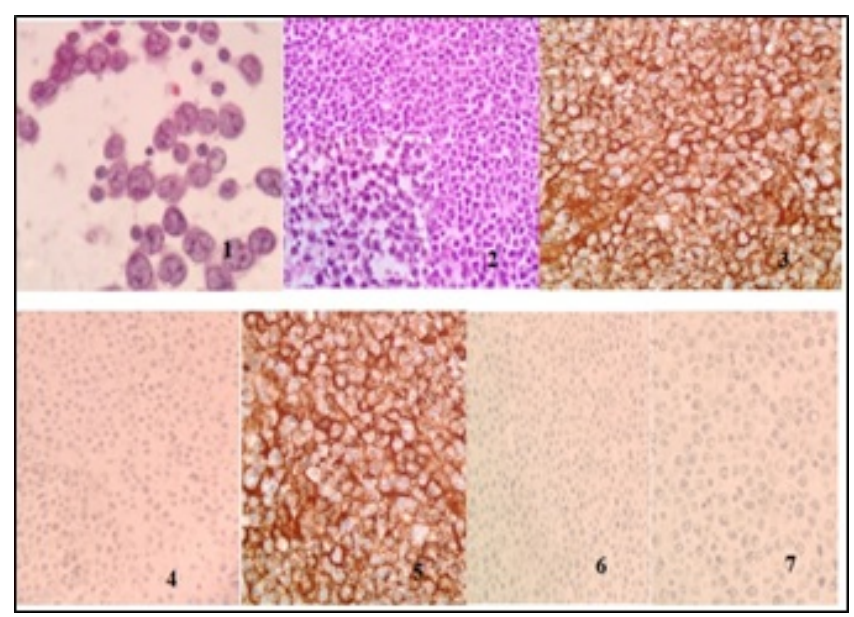

Fig-4 Metastatic Diffuse Large B Cell Lymphoma in Ascitic fluid (1) Cell smear 100x (2) Cell block 40x (Inset 100x view) (3) LCA positive (4) EMA negative (5) CD 20 positive (6) CD 30 negative (7) ALK negative. 


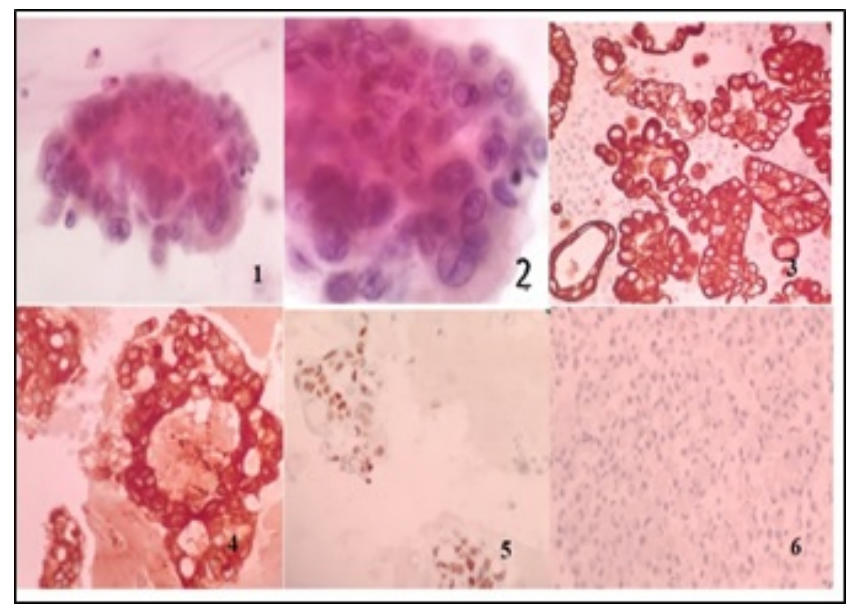

Fig-5: Metastatic Adenocarcinoma from Colon in ascitic fluid (1) Cell smear 40x (2) Cell Smear 100x (3) CK 20 positive (4) CEA positive (5) CDX2 positive (6) CK 7 negative.

All cases of malignant peritoneal effusion of gastric origin were because of adenocarcinoma. Out of the $6 \%$ metastasis cases caused to pancreato-biliary system in the present study, one half was due to pancreatic adenocarcinoma and other half was of biliary origin. This is different from the study done by Garrison et al [1].

Where $22 \%$ cases were due to pancreato-biliary system. $2.5 \%$ of the metastatic cases were caused due to breast carcinoma. $80 \%$ ( 4 cases) of breast cases were due to ductal carcinoma and $20 \%$ (1 case) were due to lobular carcinoma. It is similar to the studies done by AA Aytunde and Parsons [2] and Garrison et al [2].

All the ascitic fluid metastasis originating from oesophageal (2\%) and Colo- rectal (6\%) malignancies were adenocarcinomas (Figure 4 and Figure 5). All the cases of lung carcinoma (2.5\%) which metastasised to ascitic fluid were adenocarcinomas which highlights the propensity of adenocarcinomas to cause malignant ascites in comparison to Squamous cell carcinoma.

This finding is supported by the study done by Maria Sereno et al [16] in which $>80 \%$ of malignant ascites were due to adenocarcinomas. Rarely, the source of malignant cell in ascitic fluid was found to be Squamous cell carcinoma of cervical origin (2\%) and head and neck (1.5\%) and urothelial carcinoma of bladder $(1.5 \%)$.

Of the 11 cases that belonged to hematolymphoid origin, acute lymphoblastic lymphoma and DLBCL were detected most commonly accounting for $45 \%$ and $36 \%$ respectively followed by CML-BC
Accounting for approximately $18 \%$ cases out of total haematological malignancies. Development of serosal effusion in the course of malignant lymphomas, either primary or otherwise, is rare and is considered as one of the adverse factors affecting overall survival. However, the presence of peritoneal lymphomatosis with abdominal ascites as the first and primary presentation is rare and only few cases have been reported in the literature.

Nine cases were lost to follow up and their primary site could not be ascertained.

The present study was able to reach the confirmatory diagnosis in all these cases and pinpoint the site of origin and the histological variety of malignancy with the help of battery of

Immunohistochemistry markers based on cytomorphological features and other relevant clinical and routine investigational data. Hence, diagnosis and sub typing of the malignancy can be made on the ascitic fluid investigation itself, prompting early start of chemotherapy, and leading to long term survival benefits for cancer patients $[5,17]$.

\section{Conclusion}

To sum up, this study shows the frequency of occurrence of malignant peritoneal fluid from different varieties of cancer in different organs of human body. It depicts that cell block preparation is an effective method which increases the sensitivity of detecting malignancy in peritoneal fluid. In cases where primary site of origin is unknown, immunohistochemistry on cell block plays a vital role in detection of the site of origin which can override the need of diagnosis from primary site and start the treatment early providing, prognostic benefits to patients.

\section{What this study adds to the existing knowledge?}

Patients often present to the hospital with malignant ascites as the only symptom. Such cases highlight the role of cytopathologists in not only diagnosing malignant cells in ascitic fluid, but also in ascertaining the primary site of tumour origin. It is a daunting task especially when there are no clinical, haematological or radiological findings hinting towards the site of malignancy.

The present study showed the importance of 
Immunohistochemistry in these cases which can help in reaching a definitive diagnosis histologically. The study had 31 such cases where no primary site was available, and patient presented to us with ascitis with no sign and symptoms of malignancy elsewhere in the body. In these cases, immunohistochemical study was done on the cytoblock to diagnose the primary site of origin and later confirmed by biopsy from the primary site.

\section{Author's contribution}

Dr. Trupti Patel: Concepts, design, literature search, data analysis

Dr. Deepak Goel: Concepts, design, literature search, data acquisition, data analysis

Dr. Priti P. Trivedi: Manuscript editing

Dr. Suchita Patel: Data analysis, manuscript editing

Dr. Shailee Mehta: Manuscript editing and review

\section{Reference}

01. Garrison RN, Kaelin LD, Galloway RH, Heuser LS. Malignant ascites Clinical and experimental observations. Ann Surg. 1986;203(6)644-651.

doi: [Article:https://doi.org/10.1097/00000658198606000-00009][Crossref]

02. Ayantunde AA, Parsons SL. Pattern and prognostic factors in patients with malignant ascites- a retrospective study. Ann Oncol. 2007; 18(5)945-949.

doi: [Article:https://doi.org/10.1093/annonc/mdl499] [Crossref]

03. Runyon BA, Montano AA, Akriviadis EA, Antillon $M R$, Irving $M A$, McHutchison JG. The serumascites albumin gradient is superior to the exudate-transudate concept in the differential diagnosis of ascites. Ann Intern Med. $1992 ; 117(3) 215-220$.

doi: [Article:https://doi.org/10.7326/0003-4819-1173-215][Crossref]

04. Turnage RH, Li DLB, McDonald JC. Abdominal wall umbilicus, peritoneum, mesenteries, omentum, In- Sabiston Textbook of Surgery The biological basis of modern surgical practice. 17th ed, Philadelphia- Elsevier Saunders. 2004; 1182-1186.

[Crossref]
05. Becker G, Galandi D, Blum HE. Malignant ascites- systematic review and guideline for treatment. Eur J Cancer. 2006;42(5)589-597.

doi:

[Article:https://doi.org/10.1016/j.ejca.2005.11.018]

[Crossref]

06. Kumar SK, Verma $R$, Sachan $P$, Bahl D. Malignant Ascites of Unknown Primary Tumour Site- A Clinical Dilemma. Int $\mathrm{J}$ Surg. 2006;11(1).

[Crossref]

07. Udasimath S, Arakeril SU, Karigowdar $\mathrm{MH}$, Yelikar BR. The Role of the Cell Block Method in the Diagnosis of Malignant Ascitic Fluid Effusions. J Clinic Diagnos Res. 2012;6(7)12801283.

[Crossref]

08. Kushwaha $R$, Shashikala $P$, Hiremath $S$, Basavaraj HG. The cells in the pleural fluid and their value in the differential diagnosis. J Cytol. $2008 ; 25(4) 138-143$.

[Crossref]

09. Dekker A, Bupp PA. The cytology of serous effusions- An investigation into the usefulness of cell blocks versus smears. Am J Clin Pathol. 1978;70(6)855-860.

doi: [Article:https://doi.org/10.1093/ajcp/70.6.855] [Crossref]

10. Bonito LD, Falconieri G, Colautti I, Bonifacio D, Dudine $S$. The positive pleural effusion- $A$ retrospective study of the cytopathologic diagnosis along with the autopsy conformation. Acta Cytol. 1992; 36(3)329-32.

[Crossref]

11. Abadi MA, Zakowski MF. Cytologic features of sarcomas in fluids. Cancer Cytopathol. 1998;84(2)71-76.

doi: [Article:https://doi.org/10.1002/(sici)10970142(19980425)84:2\%3C71: :aid-cncr1\%3E3.0.co;2g][Crossref:Crossref]

12. Malik I, Abubakar S, Rizwana I, Alam F, Rizvi J, Khan A. Clinical features and management of malignant ascites. J Pak Med Assoc. $1991 ; 41(2) 38-40$.

[Crossref]

13. Parsons SL, Watson SA, Steele RJ. Malignant ascites. Br J Surg. 1996;83(1)6-14.

doi:

[Article:https://doi.org/10.1002/bjs.1800830104]

[Crossref] 
14. Gia Khanh Nguyen. Essentials of fluid cytology. UBC Pathology. 2009:9-71.

[Crossref]

15. Elisabeth Smolle, Valentin Taucher, and Johannes Haybaeck. Review- Malignant Ascites in Ovarian Cancer and the Role of Targeted Therapeutics. Anticancer Res. 2014;34(4)15531561.

[Crossref]

16. Sereno M, Rodríguez-Esteban I, Gómez-Raposo $C$, et al. Lung cancer and peritoneal carcinomatosis. Oncol Lett. 2013;6(3)705-708. doi: [Article:https://dx.doi.org/10.3892\%2Fol.2013.1468] [Crossref]

17. Kichian K, Bain VG. Jaundice, ascites and encephalopathy In- Hanks GWC, Cherny NI, Calman K, Doyle D(eds) Oxford Textbook of Palliative Medicine. 3rd edition, Oxford University Press. 2005; p507-519.

[Crossref] 